\title{
NORTHERN HARRIER KILLS AMERICAN WIGEON
}

\section{PAUL BRACE, Box 159, Rural Route 3, Saskatoon, Saskatchewan. S7K 3J6}

On 22 April 1985, approximately $10 \mathrm{~km}$ north of Wadena, Saskatchewan, an adult female Northern Harrier attacked and killed an adult male American Wigeon. Two male and one female wigeon were swimming in a pond less than $30 \mathrm{~cm}$ deep, about $20 \mathrm{~m}$ in diameter and $25 \mathrm{~m}$ east of Highway \#35. At approximately 12:00 p.m., the hawk attacked one of the male wigeon. The hawk landed on the duck and the pair struggled in the shallow water for a period of several minutes. (The other two wigeon had left.) After the initial attack, the hawk resumed flight and repeatedly flew over the duck which now appeared unable to fly. The aerial harassment caused the duck to scurry about the pond and attempt to dive in the shallow water.

At 12:04 the hawk landed on the duck a second time; the duck flapped about less vigorously. At 12:09 the duck was still struggling, but it appeared close to death. At 12:10 the hawk appeared to be stripping flesh from the duck. At that time, I left the vehicle and approached the com- batants. The duck was dead. The hawk flew off to land in a summerfallow field about $10 \mathrm{~m}$ from the edge of the pond.

Attacks by large raptors on North American ducks are not uncommon. Northern Harriers occasionally prey on waterfowl ducklings. ${ }^{3}$ However, it is generally assumed that smaller and medium sized hawks, including harriers, do not have the equipment necessary to kill a duck as large as an American Wigeon. A partial literature review revealed a report of a female Northern Harrier attempting to salvage a dead American Coot and an earlier report of the same species killing an immature American Wigeon, presumably capable of flight. ${ }^{2} 1$

1 HAMMOND, M.C. 1948. Marsh Hawk kills Baldpate. Auk 65:297-298.

2 MILLAR, J.B. 1964. Marsh Hawk attempts to salvage a dead coot. Blue Jay 22:148.

3 SOWLS, L.K. 1955. Prairie ducks. Stackpole, Harrisburg, Pa., and Wildl. Mgmt. Inst., Washington, D.C. 193 pp.

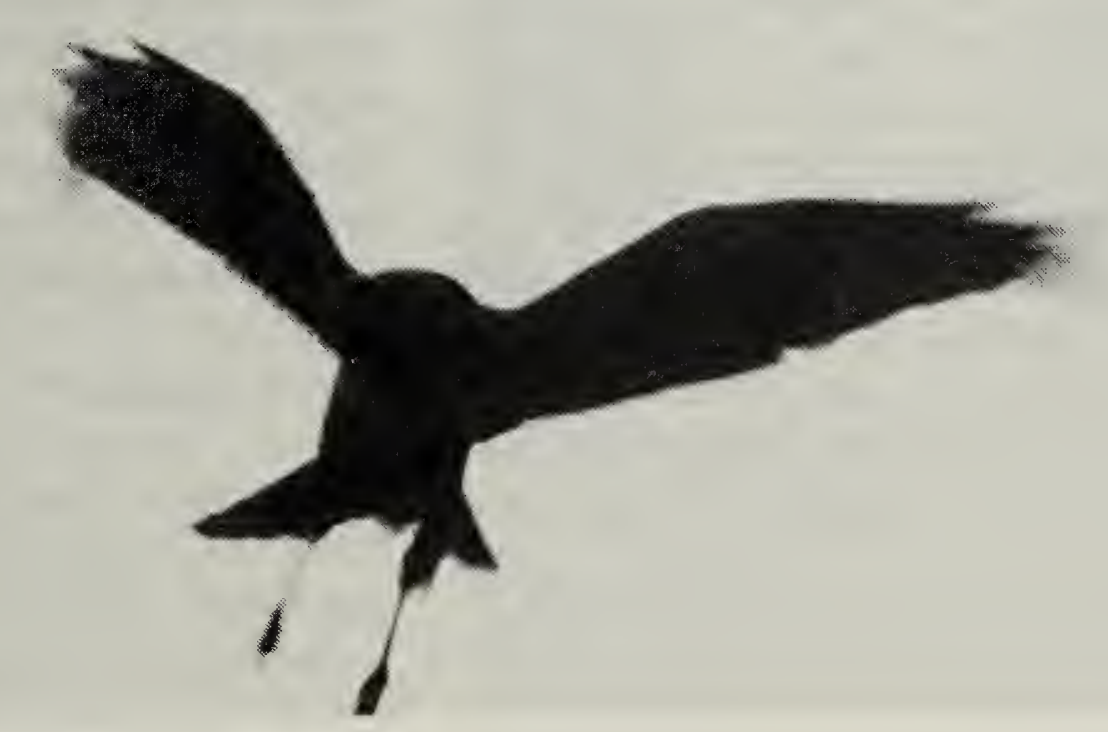

